\title{
Guest editorial note. Introduction to the contributions of the thematic issue
}

\author{
Daniela Rohrbach-Schmidt * \\ Department of Sociology and Economics of Vocational Education and Training, \\ Federal Institute for Vocational Education and Training
}

In 2003, Autor, Levy and Murnane (hereafter ALM) proposed a nuanced view on how the adoption of computer technology alters the tasks that workers perform at their jobs and hence human skill demand. The main idea of the so-called «task-approach» is to ask what tasks computers are best suited to accomplish and how these qualities complement or substitute for human job skills.

From a «machine's eye» view, and because falling costs incentivize employers, their task model intuitively predicts that computerization results in a substitution of cognitive and manual «routine» tasks, i.e. tasks that follow precise, well-understood (codifiable) rules. These tasks, e.g. bookkeeping, clerical work or repetitive assembly tasks, are typically performed by middle educated workers. On the contrary, «non-routine» tasks cannot be codified in computer software and thus workers performing these tasks have a comparative advantage over information technology. These non-routine tasks can be found at the opposite ends of the occupational-skill distribution: On the one hand, technology (as yet) would be complementary to highskilled cognitive (abstract) non-routine tasks such as testing hypotheses, medical diagnosis, and complex communication tasks. One the other hand, low-skilled nonroutine manual tasks such as truck driving or cleaning are not directly affected by computerization because they require situational, visual, or language capabilities and interpersonal communication. Together, the task-model predicts an increase in the relative demand for highly educated workers and a decline in middle-skilled workers.

Studies for the US, UK, Germany and various other European countries have found evidence in favor for the ALM hypothesis and the resulting employment polarization (see e.g. Autor \& Handel [2009] for references). Already, the task-approach has proven to be of high potential as an organizing framework for a large array of economic and sociological research questions such as research on wages, international off-shoring and trade, immigration and female employment (ibid.).

\footnotetext{
* Federal Institute for Vocational Education and Training, Robert-Schuman-Platz 3, D-53175 Bonn. Phone: 0049-228-107-2032,E-mail: rohrbach@bibb.de.
} 
In May 2010, the Institute for Employment Research (IAB) and the Federal Institute for Vocational Education and Training (BIBB) invited leading scholars of the taskapproach, including David Autor, to discuss their work at a two-day international «T.A.S.K.S. (Technology, Assets, Skills, Knowledge, Specialization) workshop» in Nuremberg, Germany. ${ }^{1}$ As a result of these joint activities a selection of presenters at T.A.S.K.S. agreed on publishing their work in this special issue. Each of the four papers discusses and empirically employs approaches that take advantage of a taskrelated or job skill requirement perspective of occupations.

In the first paper, Stijn Rocher links the task-approach to the analysis of occupational choice by investigating the extent to which vocational skills are task-specific. In his paper, he assumes that workers acquire task-specific skills prior to labor market entry and - following the Roy framework proposed by Autor and Handel (2009) - provides a framework on how skills are linked to tasks. For his empirical analysis, he merges information of the tasks content of jobs from the UK Skill survey 2006 with information on major choice and further job related information from the European Reflex dataset. His analyses show that major choice is an important determinant of job tasks. He further demonstrates that graduates from the same field selfselect into occupations with similar task content and wages.

Secondly, Regula Geel and Uschi Backes-Gellner show the merits of an analysis of occupational mobility that considers job skill requirements instead of occupational codes as a determinant of job flexibility and income. They apply Lazear's skillweight approach (2009) to apprenticeship training and study the effects of specificity of skill combinations on mobility within and between clusters of occupations with similar skill requirements. Their empirical analyses of the BIBB/BAuA Employment Survey 2005/2006 show that an apprenticeship training diploma indeed provides German graduates with occupational flexibility. The degree of flexibility however varies with the specificity of the required skill combination of an occupation.

The third paper by Michael Tiemann and Daniela Rohrbach-Schmidt takes over the task approach to the study of mismatching. The authors analyze whether there is an increase in over-qualification of differently educated groups of workers in Germany, and whether the increase is linked to changes in job tasks and polarization in employment. While they found some evidence in favor for such a linkage, their analyses of the BIBB/IAB and BIBB/BAuA Employment Surveys 1970 to 2006 moreover demonstrate that one important challenge for the task-approach is measurement.

The last paper by Michael Tåhlin gives an overview of the conceptual foundation and measurement issues related with the vertical differentation of work. In addition

1 Following up this successful event, T.A.S.K.S. II will be taking place in January 2012 at BIBB in Bonn. 
to the horizontal variation in work content as captured by tasks, he persuasively argues for understanding job complexity as the major vertical dimension of work activities. He then presents measures for this concept as given with the Swedish Level of Living Survey and the cross-national European Social Survey. Analyzing their measurement properties he reveals the high quality and utility of the job complexity indicators.

Overall, the four papers present theoretical insights and findings on the role of job tasks and skill requirements in the field of research in vocational education and training. We hope that this special issue will contribute to the development of the field by illustrating the value of the task-approach and by thereby pointing out interesting areas for future research.

Prof. Dr. Stefan Wolter, the Editor-in-Chief, deserves special thanks for his willingness to publish this thematic issue and for his helpful advices and support. I thank Dr. Günther Walden for providing this continued support in realizing this issue. Finally, I am indebted to the ten reviewers and to all authors for their excellent contributions.

\section{References}

Autor, D. H., \& Handel, M. J. (2009). Putting Tasks to the Test: Human Capital, Job Tasks and Wages. MIT Working Paper and NBER Working Paper No. 15116. Cambridge MA: NBER

Autor, D. H.; Levy, F. \& Murnane, R. J. (2003). The skill content of recent technological change: An empirical exploration. Quarterly Journal of Economics, 118(4), 1279-1333

Lazear, E. P. (2009). Firm-Specific Human Capital: A Skill-Weights Approach. Journal of Political Economy, 117(5), 914-939 